\title{
Missing Actions in Cluster Innovation
}

\author{
http://dx.doi.org/10.3991/ijac.v7i1.3524 \\ S. Rubach ${ }^{1}$, F.R. Johansen ${ }^{2}$ and G. Andersson ${ }^{3}$ \\ ${ }^{1}$ Østfold Research, Fredrikstad, Norway \& BI Norwegian Business School, Oslo, Norway \\ 2 Aalborg University, Aalborg, Denmark \\ ${ }^{3}$ Østfold University College, Halden, Norway
}

\begin{abstract}
This case study explores how a cluster project support innovation and value creation in the companies, and how the companies exploit the opportunities offered in the cluster project. Our findings describe missing links between the interorganizational and intraorganizational activities, which leave us with fragmented activities inside the clusterproject but outside the companies. We conclude that the challenges in supporting innovation and exploiting the opportunities offered are entangled in the missing actions and detachment between the actual business network and funded cluster.
\end{abstract}

Index Terms-Company Learning, Cluster, Business Networks

\section{INTRODUCTION}

In Norway, innovation systems [1] such as networks and clusters are developed and funded through programmes like Arena ${ }^{l}$ for the development of upcoming clusters and Norwegian Centres of Expertise ${ }^{2}$ (NCE) for mature clusters. These initiatives are inspired by Porter's cluster theories on competiveness [2] and Florida's concept of learning regions [3]. The programmes encourage the triple helix actors (academia-industry-state) [4] to collaborate in regional clusters. At cluster level initiatives are organized as time-limited ${ }^{3}$ projects, where a single facilitator or a facilitating organisation runs different activities for the participating organisations. These projects are used at policy level as a recipe for regional economic success. If a region is analysed and found not to have any such emergent system, it is strongly believed that it can and should be constructed.

However, these funded clusters are often constructed entities, which not necessarily cover the actors' actual business network [5], [6]. Therefore, strong relations known from the business networks are not necessarily found in a constructed cluster.

Based on the possible detachment between the actual business network and funded cluster we explore how a cluster project supports innovation and value creation in the companies, and how the companies exploit the opportunities offered.

\section{LITERATURE REVIEW}

\section{A. Why join a constructed cluster?}

Using Granovetter's theory of the strength of weak ties [7], the constructed cluster's asset could be the vast web of knowledge available to the participants which can be

\footnotetext{
http://www.arenaprogrammet.no/no/Om-Arena/About-Arena/

2 http://ekstranett.innovasjonnorge.no/templates/Page Meta 5652 2.aspx

Arena 3 years, NCE 10 years
}

used when needed. It could be looked at as a pool of "...resources that are available from partners and accessible through ties that a firms enter with them...that remain otherwise unavailable to the focal firm" [8, p. 552], and which reaches outside the cluster as such through the weak ties. In addition to the activities that occur in the cluster, the cluster represents unused opportinitues where actors build up a portfolio of relations, or bridges, to potential future collaborative partners.

Increasing the number of relations and possible relations subsequently increases the possibility for innovations. This is based on the view that innovation is a collective process, where crossing borderlines between different mind-sets, knowledge and skill bases stimulates new combinations - and hence innovation [9]-[11]. However, this asset must be mobilized and organized when needed. Mutual learning arenas, where company activities and learning are connected, are a way to make the potential assets of the cluster more visible and put into active use.

To join a cluster is then one (out of many possible) way to cross borderlines and allow flow of new ideas and knowledge from the outside into one's own boundary [12]. Gustavsen [13] states that whereas traditional clusters and networks have focused on what is equal, now something new can be seen. That is a focus on what's not equal, i.e. diversity. This has strengthened Gustavsen's assumption that learning is the main activity of these initiatives, highlighting a turn away from the limitations of an industrial grouping and specializations. This again puts high demands on cluster initiatives to establish both focus and simultaneously relevance for all of its participating organisations.

\section{B. Bridging cluster and company internal activities}

The facilitating organisation of a constructed cluster typically arrange workshops and creative seminars in order to generate pools of ideas which eventually can lead to new project proposals which can be sought financed through the R\&D financing systems. The cluster level depends on the different actors within the cluster to actually take part and eventually produce results through the common endeavours. Thus, the link between single executing actor's role and actions and the facilitating organisation in cluster initiative is important to understand, but are more or less taken for granted in the innovation system theories. Relating this to networks, Oddane [14, p. 1] recognizes innovation as a complex, open-ended activity requiring continuous co-creation of knowledge in interdisciplinary, interorganizational networks.

Holmqvist [15], [16] has addressed and proposed a model focused on the dynamics of organizational learning within and between organizations. This model is shown in Figure 1. 


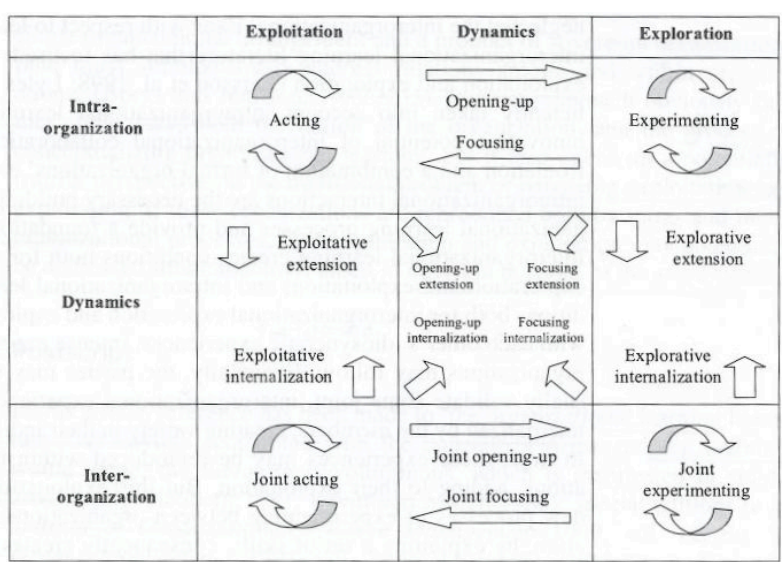

Figure 1. A dynamic model of intra- and interorganizational learning $[15$, p. 114$]$

He has sought to cross-fertilize the themes of intraorganizational learning with interorganizational learning, arguing that they are closely interlinked, but rarely done so in the organizational learning literature. In order to link them, he addresses exploration (create variety in experience by search, discovery, novelty, and experimentation) and exploitation (create reliability in experience through refinement, routinization, production, and implementation of knowledge) [16, p. 71] $]^{4}$. Further, two intermediate learning processes are proposed to tie together exploitation and exploration. Opening-up describes how exploitation generates exploration, and focusing how exploration generates exploitation.

Further, Holmqvist's intermediate processes represent the dynamics within the intraorganizational level and the interorganizational level. The interaction between the intraorganizational learning processes and the interorganizational learning processes is proposed to happen through exploitative extension, exploitative internalization, explorative extension and explorative internalization. However, diagonal inter-level learning dynamics are also included in the model, involving four different learning patterns. These are shown in the middle of Holmqvist's model cited in Figure 1.

This model is useful to explain the learning processes that are involved when a company is joining a cluster for innovation purposes. By experiencing a need for change and innovation, a company moves from their daily acting, i.e. exploitation, by opening-up over to a process of experimenting (i.e. exploration). This may cause interactions externally with other organizations, creating interorganizational learning processes.

\section{METHOD}

The case study [17] is concerned with a regional, interorganisational project that is part of the national programme Norwegian Centres of Expertise (NCE) and at the same time partly co-financed by the regional project VRI which again is part of the national programme VRI.

The national NCE programme is established to "boost innovation in the most expansive and internationally oriented industrial clusters in Norway" (NCE programme description 2008). This programme's starting point is an understanding that innovation in a knowledge economy

\footnotetext{
${ }^{4}$ The notions of exploitation and exploration were introduced by March (1991).
}

increasingly is the result of firms' interaction with their environment, and as such implies that the company is able to draw actively on ideas, impulses and specific competencies from for instance customers, suppliers, professional knowledge providers, and funding bodies (NCE programme description 2008).

The national VRI programme is designed to "develop the knowledge and ability to collaboration and innovation processes in the regions, and promote research-based innovation in Norwegian business and industry" (VRI programme description 2010). The scientific perspectives are an understanding of collaboration as coordination and implementation based on a dialogue based process and innovation as a collective and interactive process. This regional VRI projects initial goal is to increase, both in number and size, industrial $R \& D$ projects in selected focus areas in the region, where commercialization of the result is highly prioritized (Regional VRI project description).

The regional NCE, from now the NCE, appears to participating companies and the outside world as a single project independent of what programme is funding which activities.

The empirical data in this paper relates to NCE activities aimed at companies to increase innovation, the companies' participation in the NCE activities and the processes in the companies to translate learning into their own businesses.

The unit of analysis in this paper is the interactions of NCE and the participating companies. The research design could be classified as an instrumental, single case [17] and as a longitudinal process study [18, p. 194].

During the last five years the researchers has followed the NCE from taking part in seminars and workshops related to the growth of the companies. In addition, interviews and questionnaires have been used as to generate the existing data. The researchers' role has in some activities been as engaged researchers or actors [18], [19] and in others activities the role has been more as onlookers [18]. The data material consists of field notes from meetings and workshops, minutes of meetings, project documents and data from interviews.

The regional NCE is the manifestation of a larger development effort that was originally established to strengthen the IT industry in the region that eventually focused on IT-based solutions and services for the energy sector. From an open forum the development has gone through a formalized pre NCE project focusing on environmentally friendly energy trading, via a first phase of the NCE with a focus on energy and emissions trading to the current focus on smart energy markets.

The story of the NCE consists of at least three phases whereas the first phase deal with the development to be a NCE, the second phase is all about establishing the NCE as a network project and lastly to run and further develop the NCE.

\section{RESUlts}

\section{A. The Case}

The cluster in question defines itself $\mathrm{f}^{5}$ as "a cluster and a competence center that develops smart and sustainable

\footnotetext{
${ }^{5}$ http://www.ncesmart.com/Pages/Homepage.aspx
} 
energy solutions through innovation and business development". The case describes the cluster development seen through some of its major activities, as determined by some of the cluster participants and/or the cluster management. The cluster is externally funded and organized as a cluster project, and the cluster management is responsible for implementing activities to strengthen the innovation capacity in the cluster. The cluster managers organize most of these activities and also have a part in initiating most R\&D projects.

From the year 2000 the local ICT companies focused their joint efforts and organized themselves in a forum. In 2006, together with some other local and regional actors from industry and academia, they opened up for a process to apply for the status of Arena project by the Research Council of Norway. With the local industrial incubator as head applicant, they were accepted. This resulted in funding for networking activities and status as partner in a national Arena network. A major R\&D project can be regarded as an early result in this process. During 2009 the same actors applied for and were accepted as a National Centre of Expertise (NCE). The national funding was then doubled and the same applied to the actors' own efforts (time and money). The main objectives of the NCE are defined as to strengthen the cluster's expertise and through this contribute to business development and growth.

During 2011 the companies reported a lack of commercialization from the activities in the cluster. As a direct result of this the cluster management applied for funding of two knowledge liaisons, brokers between the companies and academia, to enhance the possibilities for commercialization. This measure was implemented during late fall 2012 and summer 2013, until funding was ended.

Over a longer period the cluster management has been arranging biannually seminars promoting knowledge building and the development of new ideas and possibly projects. These seminars have proved to be popular as the numbers of participating people have increased fivefold from the start to a hundred people, from industry, academia and the public sector. Ever since the beginning, there has been at least one major R\&D project running with partners from and outside the cluster. The cluster was early on focused around a small geographical spot. Today it includes actors from at least two larger national regions, with an ambition to become nationwide. .

\section{1) The pre-foresight workshop}

Through 2007 and 2008 the cluster arranged several seminars, but there was a need for a more structured approach for network development. At the time the cluster could be understood as more of a loose network without a true joint vision and aims.

In this period, the Research Council had a programme that promoted foresight as a method for developing networks. Foresight is defined ${ }^{6}$ as "a systematic, participatory, future intelligence gathering and medium-to-long term vision building process aimed at present-day decisions and mobilizing joint actions." Through firstly a meeting with the council, then followed by a meeting between the core companies in the network, they agreed to do a $1 \frac{1}{2}$ day pre-foresight workshop. This was decided as a method to get a better understanding of the concept and

http://www.forskningsradet.no/prognett-foresight/Artikkel/Foresight/ 1226485668204 to decide if this was a preferred approach by the participants.

The pre-foresight was dubbed as "a taste of a real foresight process" and had in compressed format all the elements of a full scale foresight process. The cluster management had hired an external process manager on advice from the research council. During the seminar the participants worked in groups on three main blocks; Interaction in the network, the future energy market and vision and lighthouse projects. The participants developed main goals for a full foresight process and agreed on two main points of interest to be followed up as new project initiatives. Late the first day it was announced that the network was awarded NCE status. This led to a lot of networking and discussions into the night; it was actually festivities with beheading of a champagne bottle in the night. The seminar was in the end considered a huge success and all participants were in favour of running a full foresight process over the next year.

\section{2) The foresight process}

The foresight process comprised of four subsequent workshops over a period of eight months. The whole process can be seen on one side as experimenting on for instance generating scenarios, strategies and goals, and at the same time as a joint focusing on vision, goals and strategic choices.

In the first workshop the participants developed three scenarios, based on examining the present energy market system and three (market) trends or forces they agreed on to be relatively truthfully.

In the second workshop the scenarios were used to illuminate the clusters strategic possibilities and challenges. Policies and guidelines for the cluster were discussed and lastly the participants, in groups, explored ideas for joint projects.

Vision and goals were focused on in the third workshop, where three drafts for a vision were developed. A total of 35 goals were developed through work in groups. To realize the vision and goals, there was a discussion and work in groups to develop the main strategic actions. Here the groups developed eight tasks.

The fourth workshop aimed at agreeing on the main content of a strategy for the cluster; joint vision and goals, roles and tasks, and a joint cluster strategy with measures. Through working in groups, the participants developed five roles for the project management with several measures to each role. Some of these measures were further developed into seven activities with specified people as responsible. At the workshop two versions of a focused vision were developed, and it was decided to let the cluster management process these and present a final version to the cluster board.

The last workshop and the process ended with a conclusion that "there is a need for regular meetings places in the cluster as the workshops in the foresight programme".

\section{3) The following management workshops}

Since the foresight process finished in 2010 there has been arranged seven more workshops to date. These workshops has seen a steady rise in participating people and enterprises, up to a hundred participants and more than fifty enterprises from both private and public sector. The workshops have focused on growth, business devel- 
opment and competence, and lately specifically about smart cities.

The invitations for the first of these management seminars were sent out in the name of the original NCE while the summary was sent out with a new cluster name deriving from the foresight process. At this point the cluster management also turned away from using the short form NCE "local" (i.e. the city name).

Nearly every workshop has had group work related to processes for idea generation to develop project ideas or at times some sort of priority areas. These processes have resulted in the generation of a large amount of ideas. It can be considered as a cornucopia of ideas. At times this has been an unstructured process where the idea process and the individual ideas that has been promoted has been mostly random and also with weak following up activities. Other times the processes have been planned and the outcome has been more in line with the cluster's focus and needs.

\section{4) The liaisons}

The cluster management, in a period of eight months in 2012-2013, engaged two brokers to increase commercialization in the cluster. The academy broker was set up to facilitate knowledge transfer from academia to the companies. He contributed by gathering a project group and developing an application for funding, and he was also was in charge of setting up some student projects in the companies. The industrial broker, with extensive industrial experience, arranged a series of seminars and started focusing on methods for commercializing the outcome of $R \& D$ projects. This work stopped when the funding ended. Both brokers were on part-time contracts for a short period, as the funding was limited in time and amount.

\section{5) The projects}

The cluster has as a modus operandi to initiate $R \& D$ projects. As a result the cluster management operates or is part of several R\&D projects.

The projects range from smaller pre-projects to large projects with national and international consortiums. The same businesses recur as core partners in many of the projects. The same companies have been the core of the cluster since the start-up.

An example of one of these $R \& D$ projects is the one that started up as a result of the cluster's new vision and strategy in 2010. With this project the participants set out to explore some fundamentals of the new core area and with an aim to gain new insight. A particular goal was to contribute to "economic growth in the Norwegian supplier industry related to products and services in energy trading and Smart Grid services". The consortium comprised from the start of two companies (one as project owner), two research institutions and the local incubator company. During the project it attracted two industrial partners who became test labs in the project. At the completion of the project the project owner renounced interest in the results, as it was considered to be outside their core area of interest. The most interesting results, including the developed methods and tools, was not commercialised by the participating companies at all. The results instead became the base assets of a new locally based start-up company.

6) The companies

The ICT companies and participating people in the cluster have utilized the cluster in various ways.
A new company was established late 2012 , led by experienced business executives and developers from the local milieu and with extensive international experience. The main asset for the start-up was the results and business relations gained through one of the larger $R \& D$ projects in the cluster.

The by far largest company in the cluster has from the beginning stated that their main motivation for joining the cluster has been to promote an attractive local job market. This increases the likelihood that the partners to the specialists they hire can get good jobs in the region, and as such the company becomes a more attractive employer. The company has not been active in the cluster workshops, except from giving key note presentations.

Two business developers used the cluster and the seminars as both an exploration arena for gaining new knowledge and discussing market opportunities, as well as a testing ground for the development of a new infrastructure solution. This resulted in a new company with an international market focus.

One company tried to make a transition from another sector to the energy sector, based on experiences that were deemed to be valuable in the energy sector as this is regulatory changing. The company participated in seminars, workgroups and in work related to the development of the cluster. Retrospective the company described the way to market and new customers as not possible within a reasonable period of time. The company has fallen back to its original market.

Another core company that participated in the process from the beginning and took part in one of the first major R\&D projects explained in an interview that the outcome was outside of their core strategy and that they were not interested in taking those results further. The project they took part in lasted for three years.

\section{7) Increased interest and participation}

The number of participating companies has increased in the last workshops, and at the same time the cluster has widened it's geographical focus to be nationwide. This has been done, among other reasons, to attract a sufficient base of knowledge companies. Companies are the suppliers of ICT based solutions to the energy market, but the definition is not yet fully explored.

Figure 2 shows the development of the number of total participating public and private actors versus those from companies.

As Figure 2 shows, there has been a significantly increase in the number of participants from 2012. It has also been a higher increase of non-companies (public and R\&D actors) than in the number of companies. The top was reached early 2013 followed by a slightly decrease.

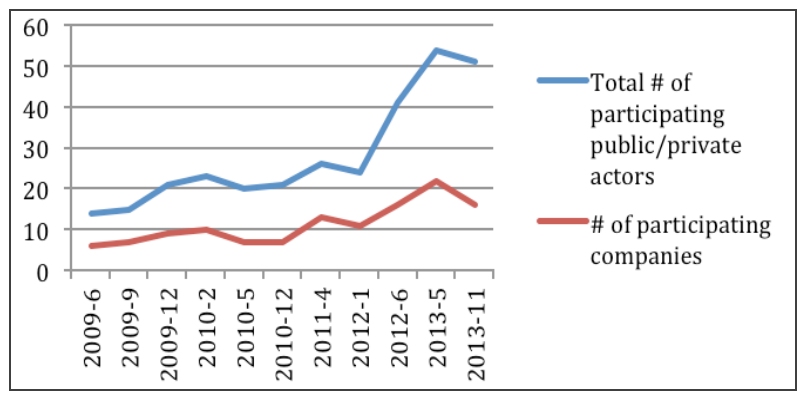

Figure 2. Public/Private Actors 


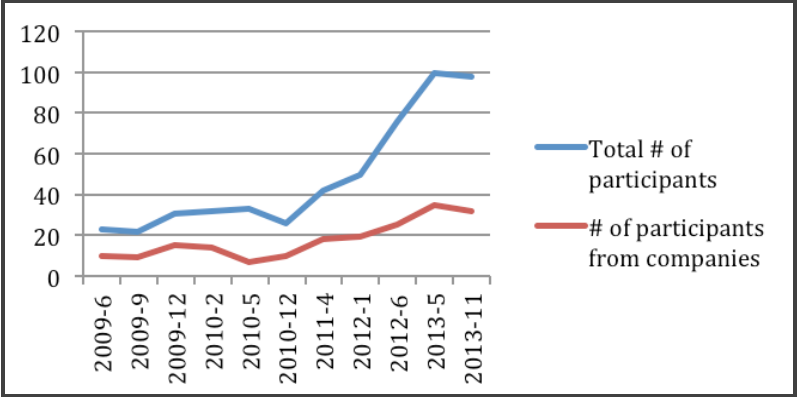

Figure 3. Participants

Figure 3 shows the number of total participants versus participants from companies (participants is here denoting to people).

Figure 3 shows a steeper increase of participants from non-companies (public and R\&D actors), and that this increase started in 2011. The top was reached early 2013 followed by a slightly decrease.

\section{ANALYSIS}

How do the case studies relate to the dynamic model of intra- and interorganizational learning?

Our case studies identify activities for exploiting and exploring new ideas and concepts in the cluster. To analyze the results we organize activities according to categories of action introduced in the dynamic model of learning discussed earlier. Table I shows the activities and categories according to this model.

The activities set up a pattern of actions shown in fig. 4 .

Figure 4 illustrates how the majority of activities, like the foresight processes, workshops and projects, focus on the interorganizational level in the cluster. Few activities address exploitative or explorative internalization and even fewer address exploitative or explorative extensions. The intraorganizational activities are neither included nor understood by the stakeholders as part of the cluster activities, illustrated in how the largest company in the cluster argues that their main objective to join the funded cluster is strengthening the attractiveness of the local community to make sure there are jobs for spouses of those they employ.

The funded cluster project lacks activities and actors making up the vertical processes in the model. We thus have isolated interorganizational initiatives but neither activities nor actors necessary to connect those to exploitation and exploration in operational strategies, activities and actions in the participating companies. We are left

\begin{tabular}{|c|c|c|c|}
\hline & Exploitation & Dynamics & Exploration \\
\hline $\begin{array}{c}\text { Intra- } \\
\text { organization }\end{array}$ & $\begin{array}{l}\text { Acting } \\
(0)\end{array}$ & $\stackrel{(0)}{\stackrel{(0)}{\rightleftarrows}}$ & $\begin{array}{l}\text { Experimenting } \\
\qquad(0)\end{array}$ \\
\hline Dynamics & (0) $\widehat{T}_{\pi}(0)$ & & $(0) \widehat{\pi}_{\pi}(0)$ \\
\hline $\begin{array}{c}\text { Inter- } \\
\text { organization }\end{array}$ & $\begin{array}{l}\text { Joint acting } \\
\text { (4) }\end{array}$ & $\stackrel{(3)}{\stackrel{(3)}{\rightleftarrows}}$ & $\begin{array}{l}\text { Joint experimenting } \\
\text { (11) }\end{array}$ \\
\hline
\end{tabular}

Figure 4. Intra- and Interorganizational Learning Activity Map
TABLE I.

Cluster ACTIVITIES OUTLINE

\begin{tabular}{|c|c|c|}
\hline Year & Activity/Milestone & Category of action \\
\hline 2006 & $\begin{array}{l}\text { Local ICT forum to apply for Arena } \\
\text { with partners from industry and aca- } \\
\text { demia }\end{array}$ & Joint opening-up \\
\hline 2007 & Awarded Arena status & \\
\hline $\begin{array}{l}2007- \\
2008\end{array}$ & Arena activities & Joint acting \\
\hline 2009 & $\begin{array}{l}\text { Not structured activities, no joint vision } \\
\text { and aims: to test foresight }\end{array}$ & Joint opening-up \\
\hline 2009 & R\&D project \#1, some actors & Joint experimenting \\
\hline 2009 & Arena to apply for NCE & \\
\hline 2009 & Full foresight process & Joint opening-up \\
\hline $\begin{array}{c}2009- \\
2010\end{array}$ & A foresight process & Joint experimenting \\
\hline 2009 & Awarded NCE status & \\
\hline 2009 & R\&D project \#2, some actors & Joint experimenting \\
\hline 2009 & $\begin{array}{l}\text { New start-up on results from ideas and } \\
\text { discussions in workshops }\end{array}$ & Joint acting \\
\hline 2010 & New focal area and new name & Joint focusing \\
\hline 2010 & New vision, strategy and aims & Joint focusing \\
\hline 2010 & R\&D project \#3, some actors & Joint experimenting \\
\hline 2010 & Continuing management seminars & Joint focusing \\
\hline 2010 & R\&D project \#4, some actors & Joint experimenting \\
\hline $\begin{array}{l}2010- \\
2013\end{array}$ & Introducing management seminars & Joint acting \\
\hline 2010 & $\begin{array}{l}\text { Management seminar \#1, Strategy for } \\
\text { implementation, of strategy and using } \\
\text { the new name (the invitations are sent } \\
\text { out in the name of the original NCE } \\
\text { while the summary are sent out with the } \\
\text { new name) }\end{array}$ & Joint focusing \\
\hline 2011 & $\begin{array}{l}\text { Management seminar \#2 and manage- } \\
\text { ment seminar \#3 on Growth through } \\
\text { new business and knowledge }\end{array}$ & Joint experimenting \\
\hline 2011 & $\begin{array}{l}\mathrm{R} \& \mathrm{D} \text { project } \# 5 \text {, industrial partner } \\
\text { opens test arena, very limited use of the } \\
\text { arena }\end{array}$ & Joint experimenting \\
\hline 2011 & R\&D project \#6, some actors & Joint experimenting \\
\hline 2012 & $\begin{array}{l}\text { Management seminar \#4 on project } \\
\text { possibilities and cluster needs }\end{array}$ & Joint experimenting \\
\hline 2012 & $\begin{array}{l}\text { Management seminar } \# 5 \text { on climate } \\
\text { changes and business possibilities }\end{array}$ & Joint experimenting \\
\hline 2012 & $\begin{array}{l}\text { Management seminar \#6 and manage- } \\
\text { ment seminar \#7 on smart cities }\end{array}$ & Joint experimenting \\
\hline $\begin{array}{l}2012- \\
2013\end{array}$ & $\begin{array}{l}\text { Introducing liaisons for mediating } \\
\text { academy and industry }\end{array}$ & \\
\hline 2013 & $\begin{array}{l}\text { R\&D project \#2 ends } 2013 \text { and new } \\
\text { start-up as results from project }\end{array}$ & Joint acting \\
\hline
\end{tabular}

with fragmented activities inside the funded cluster project but outside the companies.

Our analysis describes missing links between the interorganizational workshops, projects, seminars and ideas, and the intraorganizational strategies, activities and actions. The funded cluster is left in a static mode missing the actions necessary for the cycle of exploration and exploitation described in the dynamic model.

\section{DISCUSSION}

Our findings describe missing links between the interorganizational and intraorganizational activities. Activi- 
ties and mechanisms in the dynamic model are not present in our case, leaving us with fragmented activities inside the funded cluster-project but outside the companies.

We argue this detachment illuminates both how the cluster project support innovation and value creation in the companies, and how the companies exploit the opportunities offered. Our discussions suggest that the answers to these questions are entangled in the missing actions necessary to enable organizational learning and innovation in the companies, and thus the abilities to support innovation and exploit opportunities.

How did the cluster project support innovation and value creation in the companies? On the one side the cluster project reports high activity, numerous projects and increased engagement from the participating companies. On the other side the same companies reports only minor impact or changes in the way of doing business.

The missing link and detachment establish what we experience as two different domains. The funded cluster project makes up one domain, and the business networks make up the second. These experiences resonate with the understanding of cluster projects as idea structures [5] separated from the reality of the business networks [20], [21]. The cluster thus represents a structure outside the business networks.

The cluster project as an idea structure outside the network of actions in the companies also links up to literature on theories espoused and theories in use [22]. What the actors claim, argue and espouse, and what they actually do are not necessary the same. A company taking part in inter-organizational activities like that of the cluster project does not automatically mean that they will change the way they do business. The missing link and inconsistency in actions may thus be understood as a situation where the companies are caught up in defensive routines not able or willing to challenge the way of doing business.

But the analysis also shows a cluster project aware of the missing impact in participating companies. To increase influence and establish a link between the two domains special liaisons called knowledge brokers were introduced to develop social networking, collaborative strategy development, joint research and development projects and other measures. The liaisons where active only for a relative short period of time and used different approaches making it difficult to assess the outcome from this initiative.

How did the companies exploit the opportunities offered? The cluster project did identify business opportunities illustrated in spin-off projects and new business. But as the analysis describes, these limited opportunities where exploited by a small group of actors. The majority of companies though, did not exploit the opportunities offered. The analysis shows few activities that explicit contribute to internalization and only minor changes in the way companies do business. The analysis this way reminds us that internalization neither happen easily nor by itself.

The discussions emphasize the challenges introduced when trying to connect intra- and interorganizational activities. Mechanisms and processes discussed earlier, like the cluster as an idea structure and the defensive routines in the companies, make it difficult for the cluster project to support innovation and value creation in companies are also relevant for explaining the difficulties for the companies to exploit opportunities offered.

To exploit the opportunities offered the companies will need to analyze and plan their participation in the cluster, as to what they want to get out of it and how to act according to their goals [23]. To establish the link these intraorganizational processes at the company level must be aligned with the clusters inter-organizational processes. These premises are not in place in the cluster, as the cluster represents a structure outside the business networks.

Rubach [23] has created the dual organization development (OD) model that conceptualizes these processes and the importance of the bridge walker actively translating and implementing ideas and actions between the organizations. When the goal of participating in a network is to influence internal company development or innovation processes, then the network participation should be treated as a bridged, facilitated, intra-organization development process and inter-organization development process. The term bridged is used because the actors involved and the related activities at least pave the ground for development processes in both the participating companies and the cluster. Without the bridge, these development processes are just separate activities, where no overlaps are required to make them work. This interlinkage, called the bridge in the dual OD model, has been found to consist of three elements. Firstly - converging problem definitions and converging problem solutions. These should to be based on problem definition and problem solving both internally in each separate company and between the companies in the network and rely on what the company representatives choose to bring back and forth between their own company and the network. Secondly - the bridge walkers - who are the engaged company representatives (both the managers and relevant, skilled employees) and the network/cluster facilitator(s). They are responsible for processing and restructuring of information (knowledge and learning) back and forth, and for initiating activities in their own organization based on what they have learned. Thirdly - a common arena - for coordination, information and common activities. This part, however, is already to a great extent covered. By using these enablers, the cluster learning processes are more closely linked and converge with internal learning processes in the participating companies.

This model suggests that the cluster project and companies in the analysis miss the structures and actors making up these bridge walkers.

We conclude that the challenges in supporting innovation and exploiting the opportunities offered are entangled in the missing actions bridging the two domains.

Further research: Our study leaves us with several issues for further research. First how the findings point to increased engagement from the companies but only minor impact in the way of doing business. This paradox emphasizes the challenges in bridging the two domains as concluded in our paper but also questions our knowledge on how to bridge the domains. What actions do enable or stop exploitation of opportunities? Second how some actors manage to exploit the opportunities offered where others don't. How do some manage where so many don't? Third how the challenges met initiate actions by the facilitating cluster project. Do we have the knowledge and tools necessary to take appropriate actions? 


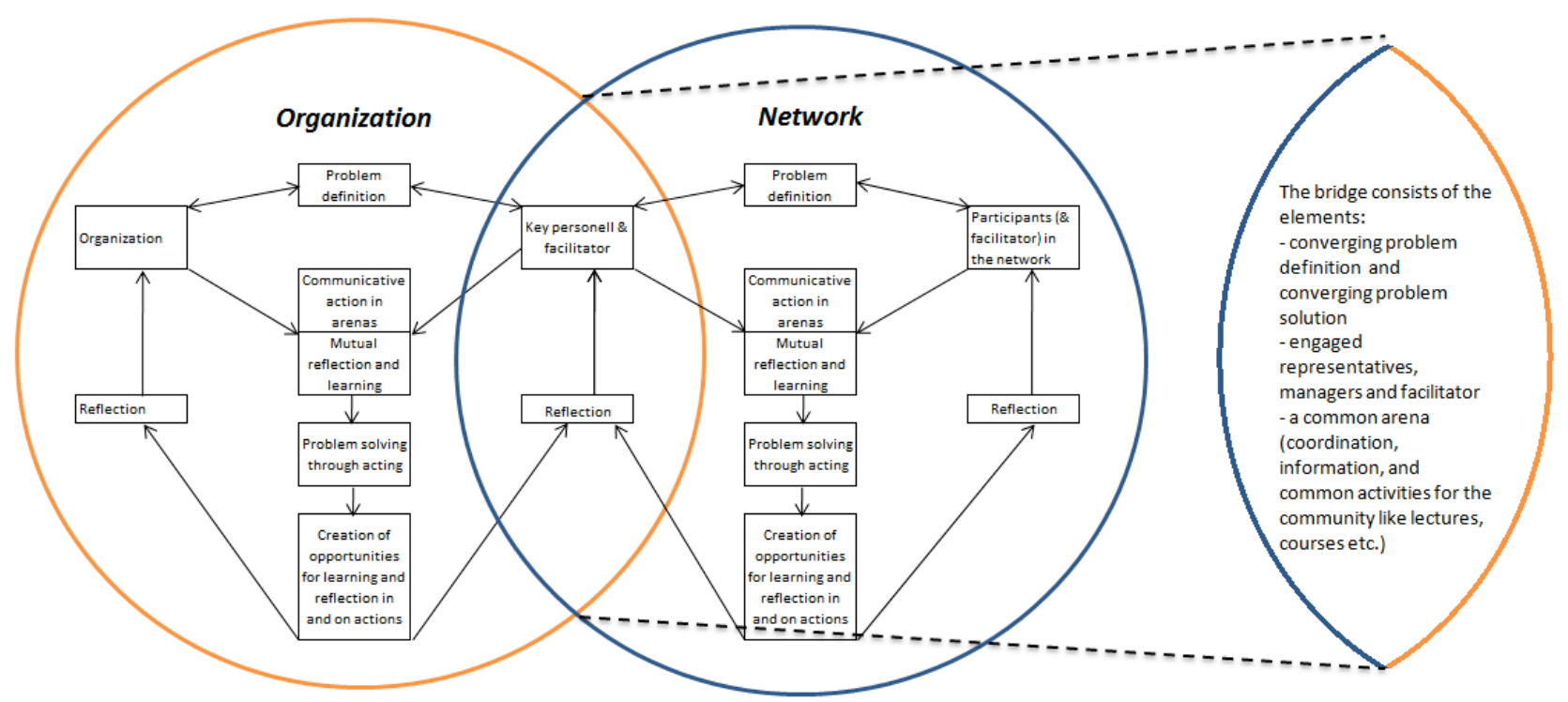

Figure 5. The dual OD model, including the bridge

\section{REFERENCES}

[1] P. Cooke, "Regional innovation systems: Competitive regulation in the new Europe," Geoforum, vol. 23, no. 3, pp. 365-382, 1992. http://dx.doi.org/10.1016/0016-7185(92)90048-9

[2] M. Porter, The competitive advantage of nations, With a new introduction. New York ;;London ;;Toronto: the Free press, 1990.

[3] R. Florida, "Toward the learning region," Futures, vol. 27, no. 5, pp. 527-536, Jun. 1995. http://dx.doi.org/10.1016/0016$3287(95) 00021-\mathrm{N}$

[4] H. Etzkowitz and L. Leydesdorff, "The dynamics of innovation: from National Systems and 'Mode 2' to a Triple Helix of university-industry-government relations," Res. Policy, vol. 29, no. 2, pp. 109-123, Feb. 2000. http://dx.doi.org/10.1016/S00487333(99)00055-4

[5] H. Håkansson, D. Ford, L.-E. Gadde, and I. Snehota, Business in Networks. .

[6] T. Hoholm, S. Rubach, and B. E. Mørk, "How can policy influence innovation in networks?: Regional innovation policy in practice," presented at the IMP Conference in ROme, Italy, 2012.

[7] M. S. Granovetter, "The strength of weak ties," Am. J. Sociol., vol. 78, no. 6, pp. 1360-1380. http://dx.doi.org/10.1086/225469

[8] R. Katila, "Technology perspective on network resources," Acad. Manag. Rev. $A M R$, vol. 33, no. 2, pp. 550-553.

[9] J. Fagerberg, "Innovation. A guide to the literature," in The $O x$ ford handbook of innovation, J. Fagerberg, D. C. Mowery, and R. R. Nelson, Eds. Oxford; New York: Oxford University Press, 2005.

[10] D. Leonard-Barton, Wellsprings of knowledge: building and sustaining the sources of innovation. Boston, Mass.: Harvard Business School Press, 1995.

[11] B. Von Stamm, Managing innovation, design and creativity. Chichester; New York: J. Wiley, 2003.

[12] A. Lam, "Organizational innovation," in The Oxford handbook of innovation, J. Fagerberg, D. C. Mowery, and R. R. Nelson, Eds. Oxford; New York: Oxford University Press, 2005, pp. 115-147.

[13] B. Gustavsen, "Noen sammenfattende perspektiver," in Nettverk: abstrakt kategori eller konkret arbeidsfellesskap?: erfaringer fra Verdiskaping 2010, B. Gustavsen, Ed. Oslo: Norges forskningsråd, Divisjon for innovasjon, 2004, pp. 76-82.

[14] T. 1965- Oddane, Organizational conditions for innovation: a multiperspective approach to innovation in a large industrial company, vol. 2008:297. Trondheim: Norges teknisknaturvitenskapelige universitet, 2008.

[15] M. Holmqvist, "A Dynamic Model of Intra-and Interorganizational Learning," Organ. Stud., vol. 24, no. 1, pp. 95-123, Jan. 2003. http://dx.doi.org/10.1177/0170840603024001684
[16] M. Holmqvist, "Experiential Learning Processes of Exploitation and Exploration within and between Organizations: An Empirical Study of Product Development," Organ. Sci., vol. 15, no. 1, pp. 70-81, 2004. http://dx.doi.org/10.1287/orsc.1030.0056

[17] R. E. Stake, "Case studies," in Handbook of qualitative research, vol. 2nd, Thousand Oaks Calif.: Sage Publications, 2000, pp. 435$436-454$.

[18] A. H. Van de Ven, Engaged scholarship: a guide for organizational and social research. Oxford; New York: Oxford University Press, 2007.

[19] M. Levin and J. E. Ravn, "Involved in Praxis and Analytical at a Distance," Syst. Pract. Action Res., vol. 20, no. 1, pp. 1-13, Jan. 2007. http://dx.doi.org/10.1007/s11213-006-9045-1

[20] G. Andersson, The assembly of lean production: an analysis of doing production improvements, vol. 2011:173. Trondheim: Norwegian University of Science and Technology, 2011.

[21] G. Andersson, "Rethinking Regional Innovation," Syst. Pract. Action Res., vol. 26, no. 1, pp. 99-110, Feb. 2013. http://dx.doi.org/10.1007/s11213-012-9265-5

[22] C. Argyris, On organizational learning, 2nd ed. Oxford: Blackwell Business, 1999.

[23] S. Rubach, "Company learning in a network: a dual organizationdevelopment (OD) process : bridging the learning processes in a network and the local learning processesin the participating company," Norges teknisk-naturvitenskapelige universitet, Trondheim, 2011.

\section{AUTHORS}

S. Rubach is with Østfold Research, 1671 Kråkerøy, Norway and BI Norwegian Business School, Oslo, (email: sr@ostfoldforskning.no).

F. R. Johansen is with the Engineering Department, Østfold University College, 1757 Halden, Norway and the Engineering and Science Department, Aalborg University, 9220 Aalborg East, Denmark (email: frode.r.johansen@hiof.no).

G. Andersson is with the Engineering Department, Østfold University College, 1757 Halden, Norway (email: gunnar.andersson@hiof.no).

This work was supported in part by The Research Council of Norway and Østfold County Council, and through in-kind hours at Østfold Research and Østfold University College.

Submitted 25 February 2014. Published as re-submitted by the authors 04 April 2014. 